\title{
Correspondence
}

\section{Change is not always for the better}

In 2004, I was working in a hospital in Kent when the sector-based approach was abandoned and the in-patient/ out-patient way of working was launched. ${ }^{1}$ This also coincided with the launching of a plethora of teams in the community. Each of these new teams was very clear of their exclusion criteria but a lot less clear about everything else.

Whenever I tried to question the evidence of this approach I ran the risk of being accused of impeding progress. It gradually came to me that this approach was not just the symptom of the malady of change for change's sake but of something far more sinister. It was borne out of a dislike of consultants. A manager actually blurted it out: 'Your little empires are being demolished!'

I did the only thing I could do at the time. I fled as far away as I could from the influence of such half-baked ideas. I am happy to report that up here in the Highlands of Scotland things are still very traditional and they work much, much better.

1 Laugharne R, Pant M. Sector and functional models of consultant care: in-patient satisfaction with psychiatrists. Psychiatrist 2012; 36: 254-6.

Isaac Sundeep is a consultant psychiatrist at New Craigs Psychiatric Hospital, Leachkin Road, Inverness IV3 8NP, UK, email: isaac.sundeep@nhs.net

doi: $10.1192 / p b .36 .10 .397$

\section{Striving for equal healthcare for prisoners}

I admire the positive efforts of Davies \& Dimond, ${ }^{1}$ but my views are more aligned with those expressed by Wilson. ${ }^{2}$ The Mental Health Act 1983 (as amended) does indeed apply in prisons. I have some further points to raise.

Clinicians working in prisons are likely to be aware of common debates between the healthcare workers and other staff. First, the status (prisoner v. patient) of a detained person; second, the related issue of health needs $v$. security needs - in practice, it is often the non-healthcare staff whose views prevail.

An important point to remember is that early active treatment of psychotic symptoms is not always desired. The initial concerns are often reported by prison officers with variable (often too little) training in mental health issues and can be unreliable. Even when observed correctly, symptoms do not necessarily indicate one specific diagnosis - psychiatric expertise is required for a careful evaluation. This is best carried out in hospital as prisons restrict movements (and behaviours) even on healthcare wings, making mental state examinations difficult.

The use of injectable medications requires monitoring and psychiatric reviews which, put mildly, are not easily carried out in prison settings. Davies \& Dimond advocate depot medication to avoid repeat injections; this argument does not hold as medication in the format of short-acting injections may still need to be administered repeatedly while the depot takes time to have its desirable effects. Furthermore, the desirable effect may be a problem in itself. In the absence of adequate safeguards, I fear a slippery slope scenario. The use of depot psychotropic medication for non-psychiatric reasons may become commonplace in prisons.

Although there has been some progress, the services afforded to patients in prisons still fall short when we review issues such as length of time taken to transfer people from prison to hospital and the provision of psychological therapies in prisons.

In my view, the management plans, where indicated, should include an early transfer to a hospital setting under the available provisions of the Mental Health Act. This approach will help us to achieve the much discussed healthcare equivalence for prisoners that has been advocated for more than a decade. ${ }^{3}$ This practice also upholds the principles endorsed by Lord Bradley. ${ }^{4}$

1 Davies S, Dimond C. The Mental Capacity Act and mental healthcare in prison: opportunities and challenges. Psychiatrist 2012; 36: 241-3.

2 Wilson S. Compulsory treatment in prison. Commentary on ... The Mental Capacity Act and mental healthcare in prison. Psychiatrist 2012; 36: 243-4.

3 Department of Health. Changing the Outlook: A Strategy for Developing and modernising Mental Health Services in Prisons. Department of Health, 2001.

4 Bradley K. The Bradley Report: Lord Bradley's Review of People with Mental Health Problems or Learning Disabilities in the Criminal Justice System. Department of Health, 2009.

Aamir Ehjaz, Clinical Director, Forensic Mental Health Services, Northamptonshire Healthcare NHS Foundation Trust, UK, email: aamir@doctors.org.uk

doi: 10.1192/pb.36.10.397a

Authors' reply: Both Wilson and Ehjaz are right to highlight the fact that the Mental Health Act does allow for the transfer to hospital of prisoners who are assessed as meeting the criteria for urgent treatment. However, our thinking occurs in the context of considering what is in the best interests of mentally ill non-capacitous patients in prison where the consent to treatment provisions of the Mental Health Act do not apply. We explored whether the Mental Capacity Act could assist in rationalising both medical treatment and other aspects of care, such as enforced washing of non-capacitous patients in their best interests, in particular in light of case law concerning Article 3 of the Human Rights Act highlighting breaches which may occur from omissions of treatment (e.g. from offering no treatment while awaiting potential transfer to hospital).

In relation to juveniles, there are adequate numbers of secure hospital beds available and well-developed links between the in-reach team and the psychiatrists with access to beds hence transfer to hospital is speedy. However, in relation to the over 18-year-olds there is often a significant delay in patients being assessed and accepted by the relevant hospital, which is not infrequently compounded by disagreements about whether they are unwell enough to meet 